\title{
A note on precise tracking of suckling position by piglets
}

\author{
Janko Skok and Dejan Škorjanc \\ Department of Animal Science, Faculty of Agriculture and Life Sciences, University of Maribor, Hoče, Slovenia
}

\begin{abstract}
Piglets establish a relatively stable teat order after the first week of lactation, when each piglet chooses a preferred teat or teat pair where they tend to suckle permanently. The mechanism underlying the choice that leads each piglet to the same suckling position is still not clarified. In the present case study, piglets with different preferred suckling positions (anterior, posterior) were transferred to a foster sow after completion of the regular 4 weeks of lactation by their biological mother. For both sows, which were identical based on parity, litter size and farrowing date, we examined the suckling positions of the experimental piglets. Piglets occupied exactly the same suckling positions on both sows. Thus, piglets precisely track positions on the mammary complex of a sows udder even when previously learned discriminable stimuli have been changed, such as odours, tastes, morphologies (of sows udder or the sow itself), vocalizations, and neighbouring littermates. Our observation indicates that the spatial configuration of the mammary complex, which is determined by two parallel rows of teats arranged in pairs, can hypothetically be proposed as an important cue for piglet suckling orientation. Therefore, additional attention should be given to the exact spatial position of piglets (and vacant positions) on the mammary complex of biological and foster mothers in order to reduce stress from cross-fostering, which is standard practice in contemporary piglet production.
\end{abstract}

Keywords: piglets, teat order, suckling orientation, mammary complex, spatial configuration 


\section{Introduction}

Knowledge of pig cognition is of great importance considering the anatomical and developmental similarities between pig and human brain (Lind et al. 2007). However, in addition to the use of pigs as a suitable animal model for human neuroscience, pig welfare may be also enhanced by a greater knowledge of the cognitive mechanisms underlying pigs' behaviour.

Previous studies have firmly elucidated the spatial learning and memory abilities of both adult and neonatal piglets, their aversive and appetitive learning abilities, sensory capacities, recognition of conspecifics, and other cognitive abilities (see review by Gieling et al. 2011). Many of these cognitive abilities in pigs can be proposed to play an important part in neonatal piglets choice of a preferential suckling position (teat or teat pair), and its permanent use during lactation. Nevertheless, it is still unclear what cues lead neonatal piglets to persistently establish their own suckling position on the mammary complex.

Due to competition for suckling positions with littermates (De Passillé \& Rushen 1989), piglets experience intense, naturally induced aversive learning from the very beginning of their lives. Successful competitors are rewarded with milk from the obtained teat, and the piglets that miss suckling likely experience hunger. To avoid such costly behaviour throughout lactation, piglets learn a position where they have successfully accessed a teat or teat pair and tend to exploit this position persistently. Process of teat-order formation in piglets normally starts as group suckling cohesion immediately after farrowing (Skok \& Škorjanc 2014). After the first week post-partum, piglets already choose a preferential suckling position that they tend to primarily occupy when suckling thereafter (De Passille et al. 1988, Puppe \& Tuchscherer 1999, Skok \& Škorjanc 2013). Stable teat order reduces energy demands and fighting among littermates, which consequently increases survival rates (Hartsock et al. 1977). Various factors may contribute to teat preferences (McBride 1963, Rosillon-Warnier \& Paquay 1984), such as milk productivity (Jeppesen 1982a), specific odours and tastes of teats (Jeppesen 1982b), proximity to the sows head and vocalizations (Castrén et al. 1989, Kasanen \& Algers 2002), morphological characteristics of teats (Jeppesen 1982b), or recognition of littermates (Ewbank et al. 1974, McLeman et al. 2005).

Use of the spatial properties of the surrounding environment to locate places is known to occur in a range of vertebrate species (Cheng \& Newcombe 2005), but has not yet been studied in the suckling behaviour of neonatal piglets. However, geometrical constraints of the mammary complex have a significant influence on piglets' distribution along the mammary complex (Skok \& Škorjanc 2013). Indeed, the spatial configuration of the mammary complex, which is determined by two parallel rows of teats arranged in pairs, remains constant throughout lactation. We therefore propose that piglets are able to use the spatial configuration of the mammary complex to orient themselves and maintain their preferential suckling position.

\section{Material and methods}

This study was carried out according to the law regulating the Protection of Animals RS 51005/91-1/58 (2007), EU directive 86/609/EEC and Guidelines for the Treatment of Animals (2013). 


\section{Animals, housing, and management}

The experiment was conducted at the Pig Research Centre of the University of Maribor, Faculty of Agriculture and Life Sciences, Slovenia. In order to eliminate the effects of parity, litter size, and farrowing date, all sows included in the experiment were equalized with regard to these characteristics. Therefore, two sows from parity five with their litters, farrowed on the same day, were included in the experiment. Both sows had the same position in the farrowing crates and an equal litter size of 10 piglets.

Ten days before the expected date of parturition, the sows were transferred into individual farrowing crates (area of $4.5 \mathrm{~m}^{2}$, including $1.98 \mathrm{~m}^{2}$ of plastic-coated perforated floor). The crates were physically separated and placed in different rooms. The crates had solid wooden sidewalls and were equipped with a sow feeder and a nipple drinker. All farrowing crates were washed and disinfected before experiments began and were cleaned out daily. During the entire lactation period, piglets had free access to water. At 10 days of age, they were offered »pre-starter« creep feed ad libitum.

\section{Suckling observation and experimental design}

The piglets were marked with different combinations of dots and lines. Large individual marks were painted on the backs of the piglets within $24 \mathrm{~h}$ post-partum, and the marks were maintained throughout the experiment. Piglets' suckling behaviour was observed and the teat order was recorded on days 1, 4, and 7 (week 1), 10 and 14 (week 2), 18 and 21 (week 3), and 25 and 28 post-partum (week 4). The 28th day post-partum was the last day of lactation. On each day of observation, suckling behaviour was recorded for three hours or until at least two consecutive successful sucklings were recorded. Piglets normally suckled two to four times during a single observation. Altogether, 29 sucklings were observed during lactation. The teat order positions of the individual piglets were recorded at sucking (i.e., milk let-down). The exploitation of more than one teat during suckling (multi-teat suckling) was considered in the analysis.

The mammary complex of the sow was categorized in relation to teat pairs. Both sows had seven teat-pairs ( 14 teats), which were not injured or defective. The teat pairs were numbered 1-7 from cranial to caudal. In addition, the mammary glands were categorized in accordance with Kim et al. (2000), with the first and second teat pairs defined as 'anterior' glands, the third, fourth, and fifth teat-pairs defined as 'middle' glands, and the sixth and seventh teat pairs defined as "posterior " glands.

After the completion of regular lactation, the two lightest piglets with approximately the same body weight ( 5.20 and $5.25 \mathrm{~kg}$, respectively) were chosen from the observed litter and transferred to the foster sow for an extra week of lactation. Both had completely stable suckling positions at the different parts of the udder on their biological mother, whereby one of them suckled exclusively on the anterior glands (teat pair 2) and the second suckled exclusively on the posterior glands (teat pair 6) of the mammary complex (Figure 1). The foster sow finished regular lactation on the same day as the observed sow. A new litter was arranged by introducing the two newcomers from the observed litter and continuing access for the four lightest ( $<6 \mathrm{~kg}$ ) foster sow piglets (»residents«). On the first and fifth day of extended lactation, the suckling position of the two newcomers was examined over three consecutive sucklings. 


\section{Results}

During the first week of regular lactation, the two experimental piglets had already well developed suckling fidelity, with one at the second and one at the sixth teat pair. In this period, some suckling at neighbouring teat pairs continued to be observed. After the first week of regular lactation, both of the experimental animals had established completely stable suckling positions and suckled exclusively at a single teat pear (Figure 1).

We recorded three consecutive missed sucklings immediately after the experimental piglets arrived to the foster sow. However, during later elongated lactation, the two experimental piglets occupied and remained at the same suckling position (teat pair) on the foster sow as they had occupied on their biological mother (Figure 1).

Whereas in the original litter they mostly used one of the teats in the pair (proportion of multi-teat suckling during regular lactation ranged from $7 \%$ for $\mathrm{P} 1$ to $28 \%$ for $\mathrm{P} 2$ ), they always exploited both teats in the occupied teat pair on the foster sow (i.e., teats 3-4 and teats 11-12).
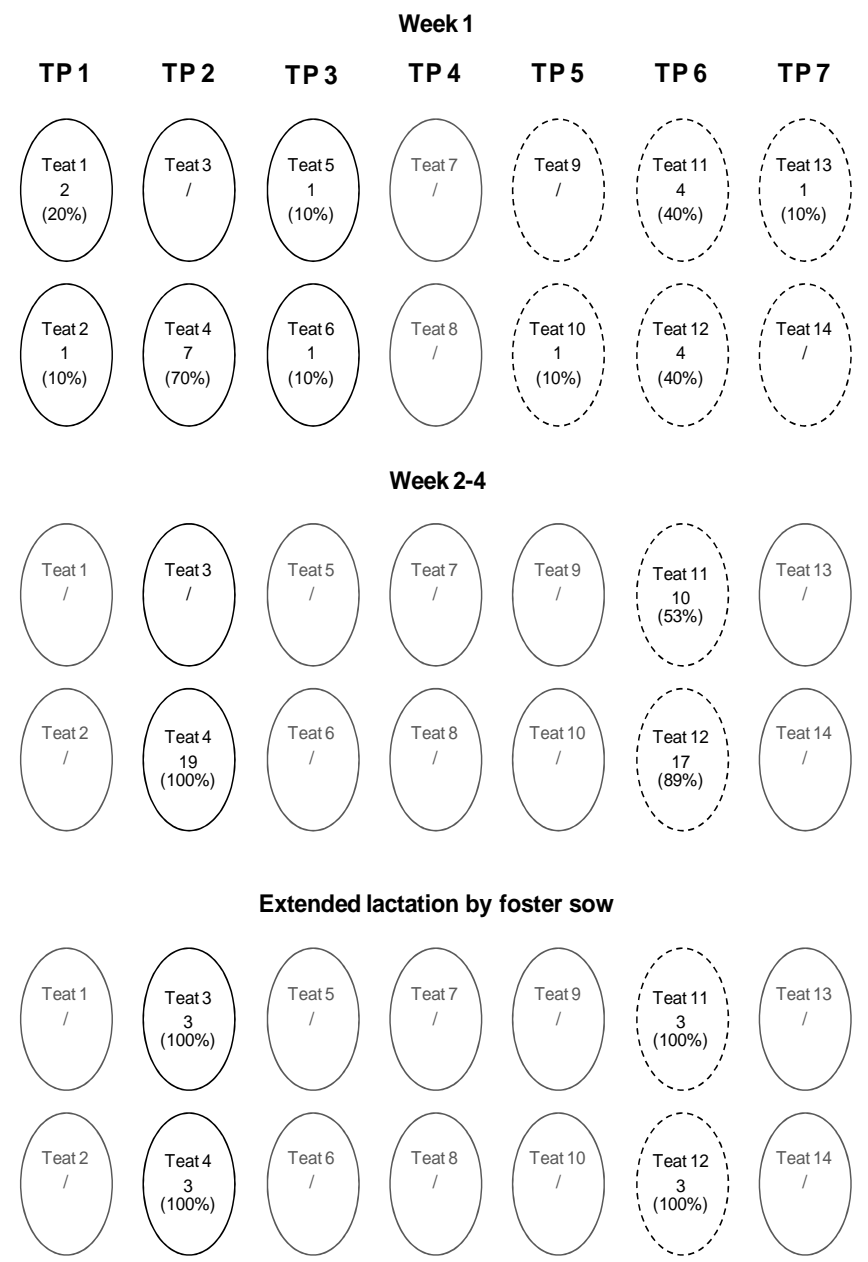

Figure 1

Suckling pattern of experimental piglets (P1and P2--) in their original litter and on a foster sow on day 5, after stable suckling positions had been established. Number of sucklings observed on a single teat or teat pair (TP) and proportion of single teat use are schematically described. Multiple-teat suckling was considered in the calculation of the teat use proportions (if two teats were exploited in one suckling session, both teats were treated as $100 \%$ used). 


\section{Discussion}

In the present case study, the majority of the potential cues that piglets could use for positioning of a teat or teat pair were changed after piglets were transferred to the foster sow, with the exception of the spatial configuration of the mammary complex. Experimental piglets found and exploited exactly the same positions on the mammary complex of the foster sow. These preliminary results support the hypothesis that the spatial configuration of the mammary complex, defined by two parallel rows of teats arranged in pairs could be an important cue in the development and maintenance of suckling positions by neonatal piglets. It can also be hypothesized that this spatial cue predominates over odours, tastes, vocalizations, morphologies (of sows udder or the sow itself), and recognition of conspecifics. It is important to note that the small sample size in the present case study resulted from our intention to reduce the impact of litter size, parity, and farrowing date (cf. Materials and methods). In addition, for elongated lactation, appropriate individuals from given litters had to be available (i.e., two light piglets that were completely stable in suckling on different parts of the mammary complex by their biological mother as well as a sufficient number of light piglets in the foster litter). Indeed, it is exceedingly rare to find a situation where all of these conditions are available, especially in systems where reproduction is natural (i.e., not manipulated through the use of hormonal treatments). However, our preliminary results provide a good platform to derive hypothetical suggestions on how piglets' learning of suckling position and their orientation on the mammary complex operates.

Using more than one criterion, such as odours, tastes, teat morphologies, recognition of littermates, and vocalizations of the sow may facilitate suckling positioning, but orienting precisely in the spatial configuration of the mammary complex may be a more reliable mechanism. Research on pigs' foraging behaviour has shown that they are able to use visual and olfactory cues to navigate, rather than solely spatial memory (Croney et al. 2003). Moreover, olfactory stimuli can influence the teat order (Jeppesen 1982b), and in combination with some other stimuli (e.g., visual and tactile) helps with the recognition of conspecifics (Meese et al. 1975, Mendl et al. 2002, Kristensen et al. 2001, McLeman et al. 2005, Souza et al. 2006). Sow vocalizations affect piglets primarily by calling them to nurse and providing signals during nursing, such as when milk ejection initiates (Algers 1993, Kasanen \& Algers 2002). Milk productivity itself cannot be used in this choice because it depends on piglet body weight and mammary gland stimulation (King et al. 1997). However, piglets can discriminate among auditory, olfactory, visual, and tactile stimuli immediately after birth (Parfet \& Gonyou 1991). It is tempting to postulate that odour and tastes, littermate recognition, and sow vocalizations are unreliable marked for suckling positioning, as odours and tastes can be masked or washed out, sow vocalizations can be obscured or disturbed because of various environmental noises, and neighbouring littermates can die. Moreover, the morphology of the mammary complex varies throughout lactation depending on teat use and the period of lactation (King et al. 1997). Despite the fact that local factors are not stable, spatial configuration of the mammary complex remain unchanged during lactation (two parallel rows of teats arranged in pairs) and therefore represent the only constant cue supporting piglets learning of suckling positions. Although geometrical constraints of mammary complex significantly affect the distribution of piglets during suckling at the 
beginning of lactation (Skok \& Škorjanc 2013), later in lactation geometrical features seem to be important for piglet suckling orientations.

Cross suckling is a natural behaviour that occurs in matriarchal groups (Olsen et al. 1998). Nevertheless, the proportion of cross-suckling in natural and semi-natural conditions is often relatively low (Newberry \& Wood-Gush 1985, Jensen 1986, Olsen et al. 1998). In contemporary piglet production, cross-fostering is standard practice, yet the stress of this process often disrupts suckling relationships and the growth performance of piglets in treated litters (Horrell \& Bennett 1981). For this reason, the effective management with sows' litters demands detailed knowledge of the piglets' behaviour. The present preliminary results underscore the importance of the spatial configuration of mammary complex in suckling behaviour and may be valuable for the welfare of cross-fostered piglets. Thus, additional attention needs to be given to the exact spatial position of piglets on the mammary complex of the biological mother and vacant positions by the foster mother in order to reduce stress caused by crossfostering. However, further research is needed to unravel how neonatal piglets use spatial/ geometric information by tracking their preferred suckling position.

\section{Acknowledgements}

The authors thank Jožica Krajnc from the Pig Research Centre (Faculty of Agriculture and Life Sciences, University of Maribor, Slovenia) for her contribution in the implementation of the experiment. The study was partially founded by Slovenian Research Agency (P1-0164 Programme Research). We also thank anonymous referees for helpful comments on an earlier version.

\section{References}

Algers B (1993) Nursing in pigs: communicating needs and distributing resources. J Anim Sci 71, 2826-2831

Castrén H, Algers B, Jensen P, Saloniemi H (1989) Suckling behaviour and milk consumption in newborn piglets as a response to sow grunting. Appl Anim Behav Sci 24, 227-238

Cheng K, Newcombe NS (2005) Is there a geometric module for spatial orientation? Squaring theory and evidence. Psychon Bull Rev 12, 1-23

Croney CC, Adams KM, Washington CG, Stricklin WR (2003) A note on visual, olfactory and spatial cue use in foraging behavior of pigs: indirectly assessing cognitive abilities. Appl Anim Behav Sci 83, 303-308

De Passillé AMB, Rushen J, Hartsock TG (1988) Ontogeny of teat fidelity in pigs and its relation to competition at suckling. Can J Anim Sci 68, 325-338

De Passillé AMB, Rushen J (1989) Suckling and teat disputes by neonatal piglets. Appl Anim Behav Sci 22, 23-38

Ewbank R, Meese GB, Cox JE (1974) Individual recognition and the dominance hierarchy in the domesticated pig. The role of sight. Anim Behav 22, 473-480

Gieling ET, Nordquist RE, van der Staay FJ (2011) Assessing learning and memory in pigs. Anim Cogn 14, 151-173

Guidelines for the treatment of animals in behavioural research and teaching (2013) Anim Behav 85, 287-295

Hartsock TG, Graves HB, Baumgardt BR (1977) Agonistic Behavior and the Nursing Order in Suckling Piglets: Relationships with Survival, Growth and Body Composition. J Anim Sci 44, 320-330

Horrell I, Bennett J (1981) Disruption of teat preferences and retardation of growth following cross-fostering of 1-week-old pigs. Anim Prod 33, 99-106

Jensen P (1986) Observations on the maternal behaviour of free-ranging domestic pigs. Appl Anim Behav Sci $16,131-142$ 
Jeppesen LE (1982a) Teat-order in groups of piglets reared on an artificial sow. I. Formation of teat-order and influence of milk yield on teat preference. Appl Anim Ethol 8, 335-345

Jeppesen LE (1982b) Teat-order in groups of piglets reared on an artificial sow. II. Maintenance of teat-order with some evidence for the use of odour cues. Appl Anim Ethol 8, 347-355

Kasanen S, Algers B (2002) A note on the effects of additional sow gruntings on suckling behaviour in piglets. Appl Anim Behav Sci 75, 93-101

Kim SW, Hurley WL, Hant IK, Easter RA (2000) Growth of nursing pigs related to the characteristics of nursed mammary glands. J Anim Sci 78, 1313-1318

King RH, Mullan BP, Dunshea FR, Dove H (1997) The influence of piglet body weight on milk production of sows. Livest Prod Sci 47, 169-174

Kristensen HH, Jones RB, Schofield CP, White RP, Wathes CM (2001) The use of olfactory and other cues for social recognition by juvenile pigs. Appl Anim Behav Sci 72, 321-333

Lind NM, Moustgaard A, Jelsing J, Vajta G, Cumming P, Hansen AK (2007) The use of pigs in neuroscience: Modelling brain disorders. Neurosci Biobehav Rev 31, 728-751

McBride $G$ (1963) The »teat order « and communication in young pigs. Anim Behav 11, 53-56

McLeman MA, Mendl M, Jones RB, White R, Wathes CM (2005) Discrimination of conspecifics by juvenile domestic pigs, Sus scrofa. Anim Behav 70, 451-461

Meese GB, Conner DJ, Baldwin BA (1975) Ability of the pig to distinguish between conspecific urine samples using olfaction. Physiol Behav 15, 121-125

Mendl M, Randle K, Pope S (2002) Young female pigs can discriminate individual differences in odours from conspecific urine. Anim Behav 64, 97-101

Newberry RC, Wood-Gush DGM (1985) The Suckling Behaviour of Domestic Pigs in a Semi-Natural Environment. Behaviour 95, 11-25

Olsen ANW, Dybkjær L, Vestergaard KS (1998) Cross-suckling and associated behaviour in piglets and sows. Appl Anim Behav Sci 61, 13-24

Parfet KA, Gonyou HW (1991) Attraction of newborn piglets to auditory, visual, olfactory and tactile stimuli. J Anim Sci 69, 125-133

Puppe B, Tuchscherer A (1999) Developmental and territorial aspects of suckling behaviour in the domestic pig (Sus scrofa f. domestica). J Zool 249, 307-313

Rosillon-Warnier A, Paquay R (1984) Development and consequences of teat-order in piglets. Appl Anim Behav Sci 13, 47-58

Skok J, Škorjanc D (2013) Formation of teat order and estimation of piglets' distribution along the mammary complex using mid-domain effect (MDE) model. Appl Anim Behav Sci 144, 39-45

Skok J, Škorjanc D (2014) Group suckling cohesion as a prelude to the formation of teat order in piglets. Appl Anim Behav Sci 154, 15-21

Souza AS, Jansen J, Tempelman RJ, Mendl M, Zanella AJ (2006) A novel method for testing social recognition in young pigs and the modulating effects of relocation. Appl Anim Behav Sci 99, 77-87 